\title{
Ribosomal Ribonucleic Acid Homology Among Species of the Genus Veillonella Prévot
}

\author{
J. L. JOHNSON* AND BARBARA HARICH \\ Department of Anaerobic Microbiology, Virginia Polytechnic Institute and State University, Blacksburg, \\ Virginia 24061
}

\begin{abstract}
Strains of the genus Veillonella were compared by ribosomal ribonucleic acid homology (16S and 23S). The strains examined represented all species in the genus, as well as several unnamed organisms which had negligible deoxyribonucleic acid homology with each other or with any of the named species. The organisms which we studied formed three clusters with average intracluster homology values of 90 to $100 \%$ and an average intercluster homology value of 60 to $70 \%$. Veillonella parvula, Veillonella dispar, Veillonella atypica, Veillonella rodentium, and Veillonella caviae belonged to one cluster. Veillonella ratti, Veillonella criceti, and strains VPI 12095, VPI 1148B, and VPI 7944 belonged to a second cluster, whereas the two strains belonging to the " $3312 \mathrm{~A}$ " homology group represented the third cluster. Although some of the Veillonella species, as defined by deoxyribonucleic acid homology, are associated with specific host animals, this relationship does not appear to extend to the ribosomal ribonucleic acid homology clusters. For example, strains of $V$. rodentium and $V$. cricet $i$ were isolated exclusively from hamsters but belonged to separate ribosomal ribonucleic acid homology clusters.
\end{abstract}

Organisms in the genus Veillonella Prévot are anaerobic, nonmotile, nonsporulating, gramnegative cocci. They usually do not attack carbohydrates but produce propionate and acetate from lactate, pyruvate, and peptones. Most isolates have been obtained from oral cavities of humans and other animals.

In a recent study (5), we measured the deoxyribonucleic acid (DNA) similarities of the group of isolates on which the current taxonomy of the genus is based $(3,6,7)$. Although Veillonella strains are all rather similar with regard to the usual phenotypic properties, very distinct DNA homology groups are found. On the basis of our results, we elevated six subspecies to species rank and described an additional species (5). It has also been observed that some of the species are associated with specific animal hosts $(5,7)$.

The purpose of the present investigation was to determine more distant phylogenetic relationships among representatives of Veillonella species by using ribosomal ribonucleic acid (rRNA) homology experiments.

\section{MATERIALS AND METHODS}

Bacterial strains. The bacterial strains used in this study are listed in Table 1. Reference DNA and homologous rRNA were prepared from the type strain of each species and also from strains with less than $31 \%$ DNA homology with any of the type strains (5). Strain VPI 7944 was the only unique strain (as determined by DNA homology) not used as a reference. Additional information concerning the sources of these strains and their DNA relationships can be found elsewhere (5).

Nucleic acid isolation. The organisms were grown in a complex medium containing lactate, as described previously (5). High-molecular-weight DNA was isolated by the method of Marmur (4), and rRNA was isolated by using a variation of the Kirby procedure, as described previously (1). The rRNA samples that were to be iodinated were purified further, and the $16 \mathrm{~S}$ and $23 \mathrm{~S}$ components were isolated by sucrose gradient centrifugation as described by Selin et al. (7).

Iodination. Samples of rRNA $(100 \mu \mathrm{g})$ containing the $16 \mathrm{~S}$ and $23 \mathrm{~S}$ components were labeled with ${ }^{125} \mathrm{I}$ by using a variation of the Tereba-McCarthy procedure $(8,10)$. The specific activities of the preparations ranged from $3 \times 10^{5}$ to $8 \times 10^{5} \mathrm{cpm} / \mu \mathrm{g}$ of rRNA.

Hybridization experiments. The procedures used for the rRNA homology experiments have been described previously (1; Johnson and Harich, Curr. Microbiol., in press). The rRNA hybridizations were done in $4 \times$ SSC-1 mM HEPES ( $N$-2-hydroxyethylpiperazine- $N^{\prime}$ 2-ethanesulfonic acid sodium salt) buffer containing $45 \%$ formamide $(1 \times \mathrm{SSC}$ is $0.15 \mathrm{M} \mathrm{NaCl}$ plus $0.015 \mathrm{M}$ sodium citrate), and the reaction mixtures were incubated at $50^{\circ} \mathrm{C}$. Each hybridization mixture contained $0.3 \mu \mathrm{g}$ of ${ }^{125}$ I-labeled rRNA, 0,30 , or $50 \mu \mathrm{g}$ of competitor rRNA, and about $4 \mu \mathrm{g}$ of DNA (immobilized on a nitrocellulose filter [ 3 by $9 \mathrm{~mm}$ ]).

The thermal stabilities of the rRNA hybrids with the DNA immobilized to nitrocellulose membranes were determined as previously described (1; Johnson and Harich, in press). The elution temperatures were increased in $5^{\circ} \mathrm{C}$ increments from 35 to $85^{\circ} \mathrm{C}$. The elution buffer was $4 \times$ SSC $-1 \mathrm{mM}$ HEPES ( $\mathrm{pH} 7.0$ ) containing $50 \%$ formamide (Johnson and Harich, in press).

A dendrogram was constructed by cluster analysis 
Table 1. Veillonella strains used in the study.

\begin{tabular}{|c|c|c|c|}
\hline Species or group ${ }^{a}$ & VPI no. & ATCC no. & Source of isolates in group \\
\hline$V \cdot$ parvula & $\begin{array}{l}11221 \\
11224\end{array}$ & $\begin{array}{l}19790^{\mathrm{T}} \\
17745\end{array}$ & $\begin{array}{c}\text { human }(17 / 45)^{b} \\
\operatorname{rat}(13 / 45) \\
\text { rabbit }(14 / 45) \\
\text { unknown }(1 / 45)\end{array}$ \\
\hline$V$. dispar & $\begin{array}{l}11223 \\
11506\end{array}$ & $17748^{\mathrm{T}}$ & human $(8 / 8)$ \\
\hline V. atypica & $\begin{array}{l}11220 \\
12102 \\
12134\end{array}$ & $17744^{\mathrm{T}}$ & $\begin{array}{c}\text { human }(30 / 31) \\
\text { guinea pig }(1 / 31)\end{array}$ \\
\hline$V$. caviae & $\begin{array}{l}12140 \\
12100\end{array}$ & $33540^{\mathrm{T}}$ & guinea pig $(7 / 7)$ \\
\hline$V$. rodentium & 11222 & $17743^{\mathrm{T}}$ & hamster $(4 / 4)$ \\
\hline "12095" & 12095 & & mouse $(1 / 1)$ \\
\hline V. ratti & 11225 & $17746^{\mathrm{T}}$ & rat $(1 / 1)$ \\
\hline$V$. criceti & $\begin{array}{l}11226 \\
12174\end{array}$ & $17747^{\mathrm{T}}$ & hamster $(15 / 15)$ \\
\hline “1148B" & 1148B & & human $(1 / 1)$ \\
\hline "7944" & 7944 & & human $(1 / 1)$ \\
\hline "3312A" & $\begin{array}{l}3312 \mathrm{~A} \\
6788 \mathrm{D}\end{array}$ & & human $(2 / 2)$ \\
\hline
\end{tabular}

\footnotetext{
${ }^{a}$ Quotation marks indicate an unnamed DNA homology group or strain.

${ }^{b}$ Number of strains from a source with reference to the total number of investigated strains in that DNA homology group. See reference 6.

$\mathrm{T}=$ type strain.
}

using the unweighted pair group method and arithmetic averages (9).

\section{RESULTS}

The rRNA homology results are shown in Table 2. The rRNA homology values ranged from 47 to $100 \%$. When competitor rRNAs were prepared from more than one strain of a species, very similar results were obtained. The reciprocal homology values among the reference strains were, for the most part, very similar. The greatest differences in reciprocal homology values were with Veillonella rodentium VPI $11222^{\mathrm{T}}$ (T $=$ type strain); with this strain differences as high as $17 \%$ were found. Only low levels of rRNA homology were detected when we used competitor rRNA preparations from Escherichia coli, Methanobacterium formicicum, and Saccharomyces cerevisiae.

Average rRNA homology values among species or strains were calculated from Table 2 and were used in a cluster analysis (using the unweighted pair group method and arithmetic averages) to construct the dendrogram shown in Fig. 1. The Veillonella species and unique strains segregated into two major clusters which usually had intracluster homology values of $80 \%$ or more and intercluster homology values of 60 to $70 \%$. The two strains in the " $3312 \mathrm{~A}$ " DNA homology group represented a third rRNA homology cluster.

Five of the labeled rRNA preparations were used in thermal stability experiments (Table 3 ). The following equation was used to obtain the regression line for the correlation between percent rRNA homology and thermal denaturation $\left[\mathrm{T}_{m(e)}\right]$ values: percent $\mathrm{rRNA}$ homology $=-0.76$ $\mathrm{T}_{m(e)}+96$ (data not shown). With one exception, the thermal stabilities of the heterologous hybrids of the rRNA preparations with more than $80 \%$ homology were less than $2^{\circ} \mathrm{C}$ lower than those of the homologous hybrids. Even with the most distantly related rRNAs, the thermal stabilities of the majority of the heterologous hybrids were only 3 to $4.2^{\circ} \mathrm{C}$ lower than the thermal stabilities of the homologous hybrids.

\section{DISCUSSION}

The genus Veillonella represents a rather homogeneous group of organisms with regard to rRNA cistrons. The intergroup rRNA homologies among even the more distantly related 
Table 2. rRNA homology values among Veillonella strains

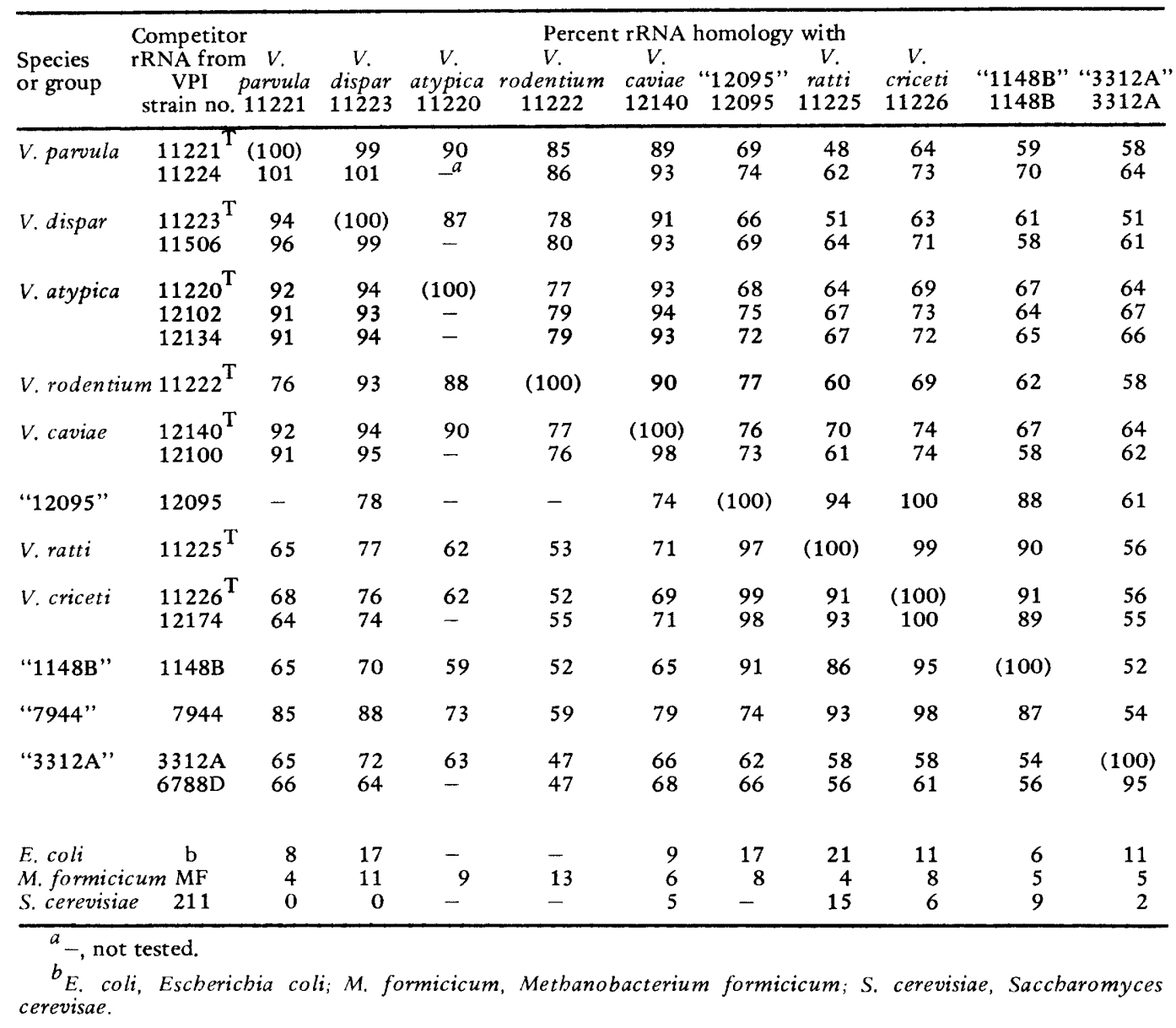

groups are in the $60 \%$ range. Also, the thermal stability values of heterologous hybrids between representatives of these groups for the most part are only 3 to $4.2^{\circ} \mathrm{C}$ below the thermal stability values of the homologous hybrids. As a result, the regression line that we obtained correlating the percent homology values with the thermal denaturation values of these organisms (Table 3) was steeper than the regression line obtained for Clostridium species (Johnson and Harich, in press). The reason for this difference is the smaller amount of weakly associated rRNA fragments (generated by ribonuclease treatment of the hybrids) that dissociated at the initial elution temperatures. It appears that the nucleotide sequence heterogeneity among the rRNA cistrons of the Veillonella species is distributed more evenly along the cistron length than it is in Clostridium species of comparable rRNA homology.

The correlations between the DNA similarities within this group of organisms and the rRNA homology results are quite interesting.
Veillonella parvula, Veillonella dispar, and Veillonella atypica have average interspecies DNA homology values that range from about 20 to $40 \%$, and $V$. rodentium and Veillonella caviae are related to this species group at an interspecies DNA homology value of about 10 to $20 \%$ (5). As might be expected from S1 nuclease DNA homology experiments, these species all belong to the same rRNA homology cluster, with $V$. parvula and $V$. dispar having the highest interspecies homology. On the other hand, interspecies DNA homology values generally were not as high among strains of Veillonella ratti and Veillonella criceti and strains VPI 12095, VPI 7944 , and VPI 1148B (5). However, these organisms all belonged to a second rRNA homology cluster of comparable homogeneity.

Traditional phenotypic properties have been of limited use for establishing taxonomic groups in Veillonella because of the low numbers of positive and variable traits (6). Rogosa found serological groupings to be the most useful characteristics in his studies (7). Additionally, we 


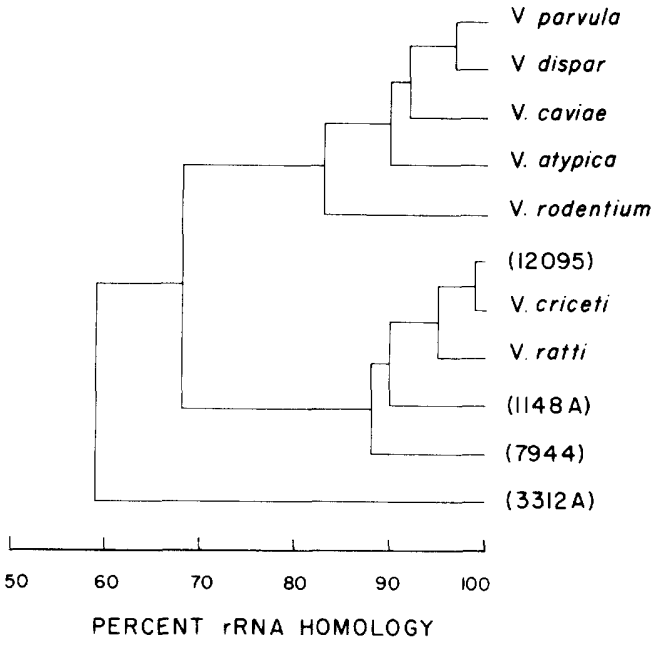

FIG. 1. Dendrogram of rRNA homology values for Veillonella species and strains. Cluster analysis of average rRNA homology values calculated from Table 2 , using the unweighted pair group method.

found that the polyacrylamide gel electrophoresis patterns of soluble cellular proteins correlate with the DNA homology groups (5). Kelly has recently shown that some of the species can be differentiated with the API ZYM system (2). Strains of $V$. parvula, V. dispar, V. atypica, and $V$. caviae exhibited both acid phosphatase and phosphoamidase activities. These are the most closely related species in one of the rRNA homology clusters (Fig. 1). Strains from the fifth species in that cluster, $V$. rodentium, also were positive for phosphoamidase activity, although not for phosphatase. Strains of two of the species in the second rRNA homology cluster, $V$. criceti and $V$. ratti, were positive for acid phosphatase.

Many of the Veillonella species appear to be asociated with specific animal hosts (5). However, species from the same or similar hosts do not necessarily have high interspecies rRNA homology. Although $V$. parvula has been isolated frequently from the mouths of humans, rats, and rabbits, $V$. dispar and $V$. typica have been isolated primarily from humans. These species, together with $V$. caviae and $V$. rodentium (isolated from guinea pigs and hamsters, respectively), form one of the rRNA homology clusters. The other major rRNA homology cluster contains $V$. criceti (isolated from hamsters) and additional strains isolated from a rat ( $V$. ratti), a mouse (strain VPI 12095), and humans (strains VPI 7944 and VPI 1148B). The third rRNA homology cluster is represented by the " $3312 \mathrm{~A}$ " DNA homology group; these two strains in this group were isolated from human clinical specimens.

Although our results do not indicate that specific hosts have a substantial impact on the rRNA clustering of the Veillonella species, our interpretations must be tempered by the small number of isolates that have been investigated, particularly for some of the DNA homology groups. Also, most of the animal isolates in the present study probably were isolated from laboratory animals, which may not reflect the oral flora of natural populations. In any event, we predict that systematic isolation of Veillonella organisms from the mouths of various wild ani-

Table 3. Differences between the thermal stabilities of homologous and heterologous rRNA hybrids,

$$
\Delta \mathrm{T}_{\mathrm{m}(\mathrm{e})} \text { values. }
$$

\begin{tabular}{|c|c|c|c|c|c|c|}
\hline \multirow[b]{2}{*}{ Immobilized DNA } & & \multicolumn{4}{|c|}{${ }^{125} \mathrm{I} 16 \mathrm{~S}+23 \mathrm{~S}$ rRNA } & \multirow{2}{*}{$\begin{array}{c}\text { "3312A" } \\
3312 \mathrm{~A}\end{array}$} \\
\hline & & V. dispar & V. rodentium & "12095" & V. criceti & \\
\hline V. parvula & 11221 & -0.2 & 0.3 & 3.8 & & 2.1 \\
\hline$V$. dispar & 11223 & $67.8^{a}$ & 1.5 & 4.1 & 3.8 & 3.0 \\
\hline$V$. atypica & 11220 & & 1.5 & 4.2 & & \\
\hline$V$. rodentium & 11222 & & $68.1^{a}$ & 4.1 & & \\
\hline$V$. caviae & 12140 & & 1.4 & 4.9 & & \\
\hline “12095" & 12095 & & 3.5 & $66.8^{a}$ & & \\
\hline V. ratti & 11225 & & 4.2 & 1.4 & & \\
\hline$V$. criceti & 11226 & 3.4 & 3.0 & 0.7 & $69.4^{a}$ & 3.7 \\
\hline "1148B" & 1148B & & & 1.8 & 1.7 & \\
\hline "7944" & 7944 & 3.2 & 3.0 & & 0.2 & 3.9 \\
\hline “3312A" & $3312 \mathrm{~A}$ & 4.2 & 3.2 & 5.7 & 5.7 & $67.4^{a}$ \\
\hline E. coli & b & 22.7 & & & & 21.1 \\
\hline
\end{tabular}

${ }^{a}$ Thermal stability values of homologous hybrids. 
mals should result in the description of new species and perhaps a correlation between rRNA homology groups and animal hosts.

\section{ACKNOWLEDGMENTS}

We thank Robert Webers, Linda Cook, and Claudine Saville for technical assistance, R. W. Kelley for aid in performing the computer analysis, and J.-S. Chen for providing cells of $M$. formicicum. Reviews of the manuscript by C. S. Cummins, L. V. Holdeman, and W. E. C. Moore are appreciated.

This work was supported by grant DEB 8001191 from the National Science Foundation.

\section{LITERATURE CITED}

1. Johnson, J. L. 1981. Genetic characterization, p. 450-472. In P. Gerhardt et al. (ed.), Manual of methods for general bacteriology. American Society for Microbiology, Washington, D.C.

2. Kelly, R. W. 1982. Phenotypic differentiation of some of the Veillonella species with the API ZYM system. Can. J. Microbiol. 28:703-705.
3. Langford, G. C., Jr., J. E. Faber, Jr., and M. J. Pelczar. 1950. The occurrence of anaerobic gram-negative diplococci in the normal mouth. J. Bacteriol. 59:349-356.

4. Marmur, J. 1961. A procedure for the isolation of deoxyribonucleic acid from microorganisms. J. Mol. Biol. 3:208218.

5. Mays, T. D., L. V. Holdeman, W. E. C. Moore, M. Rogosa, and J. L. Johnson. 1982. Taxonomy of the genus Veillonella Prévot. Int. J. Syst. Bacteriol. 32:28-36.

6. Rogosa, M. 1964. The genus Veillonella. I. General cultural, ecological, and biochemical considerations. J. Bacteriol. 87:162-170.

7. Rogosa, M. 1965. The genus Veillonella. IV. Serological groupings and genus and species emendations. J. Bacteriol. 90:704-709.

8. Selin, Y. M., B. Harich, and J. L. Johnson. 1983. Preparation of labeled nucleic acids (nick translation and iodination) for DNA homology and rRNA hybridization experiments. Curr. Microbiol. 8:127-132.

9. Sneath, P. H. A., and R. R. Sokal. 1973. Numerical taxonomy. W. H. Freeman and Co., San Francisco.

10. Tereba, A., and B. J. McCarthy. 1973. Hybridization of ${ }^{125}$ I-labeled ribonucleic acid. Biochemistry 12:4675-4679. 